\title{
A JUDICIALIZAÇÃO DA VIDA E O ATIVISMO JUDICIAL
}

\author{
LIFE JUDICIALIZATION AND JUDICIAL ACTIVISM
}

\author{
Hadassah L. Santana ${ }^{1}$ \\ Lourenço de Miranda Freire Neto ${ }^{2}$ \\ Priscila Esperança Pelandré ${ }^{3}$
}

\begin{abstract}
RESUMO
O objetivo do presente artigo científico é analisar o fenômeno do ativismo judicial, com o objetivo de encontrar parâmetros para que se possa determinar quando o mesmo deixa o âmbito da argumentação jurídica e se torna instrumento de expansão do Poder Judiciário e de eventual usurpação da função legislativa, sem olvidar da importância do papel desempenhado pelo Judiciário na manutenção democracia brasileira moderna. Parte-se da contextualização histórica que resultou no constitucionalismo e na consequente ascensão do poder judiciário, favorecido pela judicialização de questões de ordem política, moral e social, haja vista o enorme rol de direitos consagrados pela Constituição, cuja proteção demanda atuação do judiciário. Trata-se também da questão da separação dos poderes, haja vista que o ativismo enseja uma discussão que ilustra um limite transponível entre política e justiça. Aborda-se também o conceito de ativismo e sua origem histórica. Por fim, são analisados os aspectos envolvidos na interpretação do direito e a relação com a segurança jurídica, além da constatação de que a autonomia do direito em relação à política sempre será relativa.
\end{abstract}

PALAVRAS CHAVE: Judicialização; ativismo judicial; constitucionalismo; hermenêutica; segurança jurídica.

\begin{abstract}
The aim of this scientific article is to analyze the phenomenon of judicial activism, with the objective of finding parameters to determine when it leaves the scope of legal argument and becomes an instrument of expansion of the judiciary and eventual usurpation of the legislative function. without forgetting the importance of the role played by the judiciary in maintaining modern Brazilian democracy. It starts from the historical contextualization that resulted in the constitutionalism and the consequent rise of the judiciary, favored by the judicialization of political, moral and social issues, given the huge list of rights enshrined in the Constitution, whose protection demands the judiciary's action. It is also a matter of the separation of powers, since activism gives rise to a discussion that illustrates a transposable boundary between politics and justice. It also addresses the concept of activism and its historical origin. Finally, the aspects involved in the interpretation of the law and the relationship with legal certainty are analyzed, as well as the realization that the autonomy of the law in relation to politics will always be relative.
\end{abstract}

KEY-WORDS: Judicialization; judicial activism; constitutionalism; hermeneutics; legal certainty

\footnotetext{
1 Assessora legislativa tributária na Câmara Federal. Professora na pós-graduação do Instituto Brasiliense de Direito Público - IDP. Advogada no escritório Franco Jr. Advogados Associados. Doutora em Educação pela Universidade Católica de Brasília - UCB. Mestre em Direito Tributário pela Universidade Católica de Brasília.

${ }^{2}$ Doutorando em Direito Político e Econômico pela Universidade Presbiteriana Mackenzie. Mestre em Direito pela Universidade Católica de Pernambuco. Bacharel em Direito pela Universidade Federal da Paraíba. Professor licenciado da Universidade Federal da Paraíba. Atua nas áreas de direito médico, direito da saúde (seguridade social), direito constitucional, direito civil, direito processual civil e prática jurídica civil. Advogado inscrito na Ordem dos Advogados do Brasil Seccional da Paraíba.

${ }^{3}$ Advogada. Mestranda em Direito Empresarial e Cidadania pelo Centro Universitário Curitiba - UNICURITIBA. Pós-graduada em Direito Empresarial e Civil pelas Faculdades Integradas do Brasil - UniBrasil. Graduada em Direito pela PUC-PR.
} 


\section{INTRODUÇÃO}

O presente trabalho, fruto de pesquisa bibliográfica, procura analisar o fenômeno do ativismo judicial, com o objetivo de encontrar parâmetros para que se possa determinar quando o mesmo deixa o âmbito da argumentação jurídica e se torna instrumento de expansão do Poder Judiciário e de eventual usurpação da função legislativa, sem olvidar da importância do papel desempenhado pelo Judiciário na manutenção democracia brasileira moderna.

Além de meramente resolver conflitos interindividuais, o Poder Judiciário também possui a atribuição de dar concreção aos direitos fundamentais, consoante estabelece a Constituição Federal de 1988, cuja promulgação foi o ponto culminante para sua ascensão e para a ocorrência da chamada judicialização, referida pelos doutrinadores com o significado de que questões relevantes do ponto de vista político, moral e social estão sendo decididas, de forma definitiva e final, pelo poder judiciário. $\mathrm{O}$ fenômeno da judicialização ilustra o universo vasto das pretensões judicializáveis e acentua a linha tênue que existe entre política e justiça na sociedade contemporânea, e que nem sempre é nítida a divisão entre criação e interpretação do direito.

Passa-se, então, à analise da relação entre os poderes judiciário e legislativo que desemboca no princípio da separação dos poderes e que demanda estudar, também, a aplicação e interpretação da norma, ressaltando que não há muito mais espaço para uma visão idealizada do formalismo jurídico, sem perder de vista que a segurança jurídica não pode ser pensada como a existência de respostas únicas e pré-prontas para os problemas jurídicos apresentados diante do poder judiciário.

Após, é abordada a relação entre judicialização e ativismo, seu histórico de surgimento, bem como as inexatidões em relação ao conceito de ativismo, advindas de abordagens do mesmo ora como aspecto positivo, ora como negativo, apontando-se as possíveis causas de sua ocorrência e suas consequências, sendo esta a justificativa deste estudo.

\section{A ASCENSÃO DO PODER JUDICIÁRIO E A JUDICIALIZAÇÃO DA VIDA}

Desde as civilizações mais antigas a vida em sociedade é pautada por normas cujo princípio seria permitir a convivência harmônica dos seus integrantes, sendo necessário a 
existência de um sistema que garanta o respeito e o cumprimento destas normas, correspondente ao ordenamento jurídico de um Estado.

Repensar a relação entre legislação e jurisdição, ou seja, entre Judiciário e Legislativo, significa analisar a aplicação da norma, que de certa forma está ligada com uma visão de separação de poderes, "a qual é, por sua vez, veículo de uma determinada concepção de estado de direito" (RODRIGUEZ, 2011, p.3).

Segundo BARBOSA e ROCHA (2015, p. 118), o Estado Liberal, assentado na teoria da separação de poderes, privilegiou, em cada momento histórico, a atuação de um ou de outro poder, evoluindo da hegemonia do Poder Legislativo, à maior atuação do Poder Executivo na emergência do estado de bem-estar social, para o fortalecimento do Poder Judiciário,

a quem se atribuiu em muitos países, principalmente a partir da Segunda Guerra Mundial, a função de garantidor não apenas dos direitos individuais clássicos do liberalismo, mas também aqueles de segunda e terceira dimensões que ilustraram as últimas décadas do Século XX e o início deste novo Século” (2015, p. 118).

O chamado constitucionalismo liberal materializou-se com as constituições dos séculos XVIII, XIX e XX,

movimento sociopolítico típico do liberalismo que teve como marcas a defesa e proteção de um rol de direitos individuais voltados às garantias das liberdades; os limites à atuação do Estado e o controle da ação dos governantes; a arquitetura de um modelo de Estado assentado na separação de poderes e no sistema de controle de freios e contrapesos. Mais recentemente, a essas características vem sido acrescido um sistema de responsabilidades, através do qual busca-se controlar os abusos do poder de Estado (BARBOSA; ROCHA, 2015, p. 118).

O artigo $2^{\circ}$ da Constituição da República Federativa do Brasil de 1988 estabelece que os Poderes da União são independentes e harmônicos entre si, sendo eles o Legislativo, o Executivo e o Judiciário. Complementa, ainda, o artigo 34, inciso IV, o qual dispõe expressamente que a União poderá intervir nos Estados e no Distrito Federal para garantir o livre exercício de qualquer dos Poderes nas unidades da Federação. Ademais, o artigo 60, $\S 4^{\circ}$, inciso III prevê que não será objeto de deliberação qualquer proposta de emenda tendente a abolir a separação dos Poderes.

Hodiernamente uma interpretação do principio da separação dos poderes, compreende dois elementos: especialização funcional (cada órgão é especializado no exercício de uma função estatal) e independência orgânica (não pode haver meios de subordinação de um poder por outro). (FISCHER; LUTZ, 2016, p. 43). 
No Brasil, a relação entre os poderes executivo, legislativo e judiciário se insere em um sistema de freios e contrapesos, havendo uma "interpenetração com situações de exercício de funções que não são próprias a cada um dos poderes considerados. Além disso, em relação aos três poderes há mecanismos de controle recíproco, que são os freios e contrapesos, para buscar o equilibrio entre os poderes e evitar os abusos" (FIGUEIREDO; GIBRAN, 2016, p. 111).

Segundo BARROSO, “desde o final da Segunda Guerra Mundial verificou-se, na maior parte dos países ocidentais, um avanço da justiça constitucional sobre o espaço da política majoritária, que é aquela feita no âmbito do Legislativo e Executivo" (BARROSO, 2012, p. 23).

\begin{abstract}
Em que pese a adoção do sistema civil law que em tese impõe uma autocontenção ao magistrado e o estrito respeito ao texto da lei, o protagonismo do Poder Judiciário ampliou-se pós-Constituição de 1988, com o enorme rol de direitos ali consagrados e a necessidade de implementá-los, e foi melhor instrumentalizado após a Emenda Constitucional n. 45, especialmente no que se refere à questões políticas (aborto, união civil, porte de armas, etc.) e implementação de políticas públicas, tradicionalmente discutidas nas esferas do legislativo e do executivo. O protagonismo do Judiciário é favorecido pelo que se denomina judicialização da política, processo por meio do qual o Poder Judiciário passou a ocupar-se da tarefa de promover a realização dos valores positivados nos princípios constitucionais e que tem resultado em processos interpretativos cada vez mais amplos e, via de regra, uma interpretação crescentemente mais aberta da Constituição. Esse é o contexto em que se fortalece o chamado ativismo judicial (BARBOSA; ROCHA, 2015, p. 120).
\end{abstract}

Tais questões ilustram o limite transponível entre política e justiça no mundo contemporâneo. No caso brasileiro, segundo BARROSO, seria ainda mais especial em extensão e volume haja vista “circunstâncias diversas, associadas à Constituição, à realidade política e às competências dos Poderes alcançaram o Supremo Tribunal Federal, nos últimos tempos, às manchetes de jornais" (BARROSO, 2012, p. 23).

Com a Constituição de 1988 o protagonismo do Judiciário ganhou relevância diante do fato de que o magistrado passou a ter função mais ativa e presente na sociedade, para a salvaguarda de direitos fundamentais (SACONATO, 2015, p. 955).

$\mathrm{Na}$ medida que os direitos fundamentais e sociais passam a incorporar as constituições, a atividade criativa do judiciário aumenta, respaldado por uma legislação menos específica que pretende garantir de forma mais ampla tais direitos, sendo esta uma das causas da intensificação da criatividade judicial apontada por CAPPELLETTI, para o qual, “inevitavelmente, o tribunal investido da árdua tarefa de atuar a constituição é desafiado pelo dilema de dar conteúdo a 
tais enigmáticos e vagos preceitos, conceitos e valores (tarefa, claro está, altamente criativa)" (1999, p. 68).

Para BARROSO, o fenômeno da judicialização significa que questões de grande repercussão e importância política ou social estão sendo decididas pelo poder judiciário (2012, p. 23). As causas são múltiplas, sendo que a

\begin{abstract}
A primeira grande causa da judicialização foi a redemocratização do país, que teve como ponto culminante a promulgação da Constituição de 1988. Nas últimas décadas, com a recuperação das garantias da magistratura, o Judiciário deixou de ser um departamento técnico-especializado e se transformou em um verdadeiro poder político, capaz de fazer valer a Constituição e as leis, inclusive em confronto com os outros Poderes. (2012, p. 24).
\end{abstract}

A segunda grande causa seria a constitucionalização abrangente, a qual corresponde ao fato de que, sendo uma questão disciplinada em uma norma constitucional, ela se transforma, potencialmente, em uma pretensão jurídica, que pode ser formulada sob a forma de ação judicial. BARROSO exemplifica da seguinte forma: "se a Constituição assegura o direito de acesso ao ensino fundamental ou ao meio-ambiente equilibrado, é possível judicializar a exigência desses dois direitos, levando ao Judiciário o debate sobre ações concretas ou políticas públicas praticadas nessas duas áreas" (2012, p. 24). O número demandas levadas ao judiciário só aumentou: em 2015 tramitavam mais de 100 milhões de processos pelas várias instâncias dos quase 100 tribunais (NALINI, 2015, p. 22).

Segundo BARROSO, a terceira causa da judicialização seria o sistema brasileiro de controle de constitucionalidade, que é "um dos mais abrangentes do mundo", "de modo que qualquer questão política ou moralmente relevante pode ser alçada ao STF”' (2012, p. 25).

\begin{abstract}
Ao se lançar o olhar para trás, pode-se constatar que a tendência não é nova e é crescente. Nos últimos anos, o STF pronunciou-se ou iniciou a discussão em temas como: a) Políticas governamentais, envolvendo a constitucionalidade de aspectos centrais da Reforma da Previdência (contribuição de inativos) e da Reforma do Judiciário (criação do Conselho Nacional de Justiça); b) Relações entre Poderes, com a determinação dos limites legítimos de atuação das Comissões Parlamentares de Inquérito (como quebras de sigilos e decretação de prisão) e do papel do Ministério Público na investigação criminal; c) Direitos fundamentais, incluindo limites à liberdade de expressão no caso de racismo (Caso Ellwanger) e a possibilidade de progressão de regime para os condenados pela prática de crimes hediondos (BARROSO, 2012, p. 25).
\end{abstract}

Diante deste cenário, não se pode imputar ao próprio Judiciário o fenômeno da judicialização, pois ela não decorre de uma vontade ou opção ideológica ou filosófica das cortes, que deverão, quando provocados a se manifestar, o fazerem nos limites dos pedidos 
formulados e diante das hipóteses de cabimento. Nos casos relatados acima o judiciário decidiu sobre as questões que lhe foram postas porque era o que lhe cabia fazer. Pode-se afirmar que fatores como

corrupção, política como de defesa de interesses meramente partidários, bem como burocratização estatal, são três componentes sociológicos que corroboram para fortalecer o mito do juiz Hércules no subconsciente coletivo e culminar na crescente judicialização das relações sociais (TEIXEIRA, 2012 p. 38).

Não obstante a judicialização e a ideia de ativismo judicial serem fenômenos coligados, como se verá adiante, não possuem as mesmas origens e significado. Para BARROSO (2012, p. 25-31), o primeiro decorre do modelo de constituição analítica e do sistema de controle de constitucionalidade (ou seja, decorre do constituinte), já o último é uma atitude, a escolha de um modo específico e proativo de interpretar a Constituição pelo judiciário, expandindo o sentido e alcance da mesma, como se verá no próximo tópico.

\section{ATIVISMO JUDICIAL}

A atuação do Poder Judiciário aparece como um dos temas que ganha cada vez mais destaque no cenário atual brasileiro, de modo que o protagonismo do exercício da jurisdição na mediação das relações sociais, políticas e econômicas, tomou o centro dos debates da contemporaneidade.

Nesse sentido, BARROSO destaca que

\footnotetext{
Nos últimos anos, o Supremo Tribunal Federal tem desempenhado um papel ativo na vida institucional brasileira. $\mathrm{O}$ ano de 2008 não foi diferente. A centralidade da Corte - e, de certa forma, do Judiciário como um todo na tomada de decisões sobre algumas das grandes questões nacionais tem gerado aplauso e crítica, e exige uma reflexão cuidadosa. O fenômeno, registre-se desde logo, não é peculiaridade nossa. Em diferentes partes do mundo, em épocas diversas, cortes constitucionais

ou supremas cortes destacaram-se em determinadas quadras históricas como protagonistas de decisões envolvendo questões de largo alcance político, implementação de políticas públicas ou escolhas morais em temas controvertidos na sociedade (2012, p. 23).
}

Afirmou-se que ao longo dos tempos o poder judiciário vem passando por transformações no perfil de sua atuação, cujo marco, como visto, se deu com a promulgação da Constituição Federal de 1988, que revelou "um momento de uma radical modificação na forma como era concebido o exercício da jurisdição constitucional no Brasil”" (TASSANARI, 2013, 
$\mathrm{s} / \mathrm{n}$ ), "oportunidade em que o magistrado passou a ter função mais ativa na sociedade ao assegurar direitos fundamentais não regulados legalmente” (SACONATO, 2016, p. 948).

Conforme já mencionado, de forma crescente o poder judiciário vem sendo convocado a participar de questões políticas, o que ocasionou a judicialização das relações sociais, também se vê "a pressão dos diversos processos de globalização culminar na complexização das relações sociais e na necessidade de se recorrer ao Judiciário para a resolução de conflitos que outrora eram resolvidos nas demais esferas da sociedade” (TEIXEIRA, 2012, p. 41).

Para CAMPOS, nas democracias contemporâneas, verifica-se a progressiva transferência decisória, por parte dos próprios poderes políticos e da sociedade, para os magistrados e tribunais.

\begin{abstract}
Isso significa que, mais do que uma escolha deliberada das cortes, elas são requeridas, pelos diversos atores políticos e sociais, a decidir sobre conflitos cruciais contemporâneos. Ou seja, a condição das cortes como atores políticos responde, em larga medida, a fatores externos, máxime a demanda de judicialização da política. Esse fenômeno cria uma estrutura de oportunidades para que as cortes avancem seu poder político-normativo, isto é, pratiquem ativismo judicial. É neste sentido que se pode dizer ter o ativismo judicial na judicialização da política a oportunidade adequada para desenvolvimento - ativismo judicial será a escolha comportamental do juiz em aceitar a demanda de judicialização da política e ditar as soluções, certas ou erradas, para as questões levantadas. (CAMPOS, 2014, s/n).
\end{abstract}

Segundo TEIXEIRA, a origem do ativismo se deu nos Estados Unidos, especialmente com a decisão proferida no caso Lochner v. New York, mas teria sido com o historiador Arthur Schlesinger Jr., em uma matéria intitulada “The Supreme Court: 1947” que o termo ativismo judicial entrou no meio jurídico, político e popular (2012, p. 39).

Ainda sobre o ativismo no âmbito da common law, como é o caso dos Estados Unidos, afirma RAMOS que se franquia ao Poder Judiciário uma atuação mais “criativa no processo de geração do direito, torna-se bem mais complexa a tarefa de buscar, no plano da dogmática jurídica, parâmetros que permitam identificar eventuais abusos da jurisdição em detrimento do poder legislativo".

Assim, nos sistemas da common law,

Não há, pois, necessariamente, um sentido negativo na expressão "ativismo", com alusão a uma certa prática de jurisdição. Ao contrário, invariavelmente o ativismo é elogiado por proporcionar a adaptação do direito diante de novas exigências sociais e de novas pautas axiológicas, em contraposição ao "passivismo", que, guiado pelo propósito de respeitar as opções do legislador ou dos precedentes passados, conduziria a estratificação dos padrões de conduta normativamente consagrados (RAMOS, 2015, p. 112). 
O fenômeno chamado de ativismo judicial, portanto, é necessariamente amplo por não se atrelar a um específico sistema jurídico, "muito embora se revele mais próximo aos sistemas constitucionais da família romano-germânica, em que a organização do aparato estatal seja informada pelo princípio da separação dos Poderes”. Por ativismo judicial, portanto,

deve-se entender o exercício da função jurisdicional para além dos limites impostos pelo próprio ordenamento que incumbe, institucionalmente, ao Poder Judiciário fazer atuar, resolvendo litígios de feições subjetivas (conflitos de interesse) e controvérsias jurídicas de natureza objetiva (conflitos normativos). (RAMOS, 2015, p. 131).

O tema ativismo judicial é rico e complexo, segundo CAMPOS, "faz-se necessário superar o problema da indefinição conceitual, cada vez mais agravado pelo uso indiscriminado e, muitas vezes, pejorativo do termo" (2014, s/n). Sobre a falta de rigor na definição, CAMPOS esclarece que,

\begin{abstract}
Conquanto muitas das críticas ao ativismo judicial mereçam ser levadas a sério, a verdade é que a maior parte é elaborada sem a definição prévia do termo. Como advertiu William Wayne Justice, "todo esse ataque verbal na maior parte das vezes se faz na ausência de uma identificação adequada de seu próprio alvo".7 O ativismo judicial é criticado, mas raramente são fixados critérios adequados para a identificação e avaliação. Não há realmente consenso sobre o que é ativismo judicial e ele acaba significando coisas distintas para pessoas distintas. É possível haver tantas concepções de ativismo judicial quantos autores sobre o tema $(2014, \mathrm{~s} / \mathrm{n})$.
\end{abstract}

Para RAMOS, há uma sinalização claramente negativa relativamente às práticas ativistas, "por importarem na desnaturação da atividade típica do Poder Judiciário, em detrimento dos demais Poderes" (2015, p. 131), ou seja, o desrespeito aos limites normativos substanciais da função jurisdicional.

A postura ativista se manifesta por meio de diferentes condutas, que incluem: a) a aplicação direta da Constituição a situações não expressamente contempladas em seu texto e independentemente de manifestação do legislador ordinário; b) a declaração de inconstitucionalidade de atos normativos emanados do legislador, com base em critérios menos rígidos que os de patente e ostensiva violação da Constituição; c) a imposição de condutas ou de abstenções ao Poder Público, notadamente em matéria de políticas públicas. (BARROSO, 2012, p. 26).

É certo que o sistema constitucional brasileiro demanda que haja uma colaboração entre os Poderes (legislativo, executivo e judiciário), de modo que, "verificada a omissão e abuso dos outros poderes, a atuação do Judiciário é exigida pela sociedade para fazer valer o primado da Constituição e do Direito" (FISCHER; LUTZ, 2016, p.50). 
Considerando, portanto, que a noção do chamado ativismo judicial está associada a uma participação mais ampla e intensa intérprete na concretização dos valores e fins constitucionais, com maior interferência no espaço de atuação dos outros dois Poderes (FIGUEIREDO; GIBRAN, 2016, p.115), necessário fazer-se considerações sobre as características peculiares da interpretação jurídica e como ela efetivamente acontece no Poder Judiciário.

\section{O JUIZ, A INTERPRETAÇÃO DO DIREITO E A SEGURANÇA JURÍDICA}

A interpretação integra a aplicação do direito e é inerente à atividade jurisdicional, adquirindo novas configurações tendo em conta os processos de transformação do estado e da própria sociedade.

Para GRAU, interpretar o direito é concretar a lei em cada caso, ou seja, aplicar a lei, correspondendo à sua produção prática (2016, p. 56) e, ainda, destaca que os juízes devem decidir não subjetivamente de acordo com seu senso de justiça, mas aplicando o direito (a Constituição e as leis) (2016, p. 20). E complementa afirmando que isso não quer dizer que cada decisão seja matematicamente previsível, pois a lei é abstrata e geral (GRAU, 2016, p. 21).

Em análise sobre a tarefa da interpretação da norma jurídica, GRAU nega a existência de uma única resposta correta (verdadeira, portanto) para todos os casos, ainda que o interprete esteja permanentemente vinculado pelo sistema jurídico (2016, p. 66). Equivocada, portanto, a visão de que a segurança jurídica implicaria em respostas únicas e unívocas para os problemas jurídicos apresentados diante do poder judiciário (RODRIGUEZ, 2011, p. 2).

Nesse sentido, para CAPPELLETTI, toda redação, mesmo a legislativa, comporta, em certa medida, interpretação, uma vez que se trata de processo que parte do indivíduo; consequência disso é que o problema se volta não à interpretação dos juízes, mas "ao do grau de criatividade e dos modos, limites, aceitabilidade da criação do direito por obra dos tribunais judiciários” (1999, p. 21).

\footnotetext{
As soluções para os problemas nem sempre são encontradas prontas no ordenamento jurídico, precisando ser construídas argumentativamente por juízes e tribunais. Nesses casos - ao menos neles - a experiência demonstra que os valores pessoais e a ideologia do intérprete desempenham, tenha ele consciência ou não, papel decisivo nas conclusões a que se chega (BARROSO, 2010, p. 35).
}

Trata-se de uma ilusão da ideia de que o juiz se encontra na posição de simplesmente declarar o direito de maneira não criativa, apenas com os instrumentos da lógica dedutiva, sem 
envolver, assim, em tal declaração a sua valoração pessoal (CAPPELLETTI, 1999, p.33). A interpretação não seria, portanto, um ato neutro posto que feita a partir das experiências do intérprete.

Importante notar que mesmo tendo como base as normas fechadas, cuja formulação permitiria deixar menos espaço para a atuação dos juízes, seria difícil garantir que as interpretações sejam unívocas (RODRIGUEZ, 2011, p. 3).

Para CAPPELLETTI, “o verdadeiro perigo não está, portanto, em que os juízes sejam criadores do direito e como tais se apresentem, mas que seja pervertida a característica formal essencial, isto é o modo do processo jurisdicional" (1999, p. 130).

Conforme ensinam ROCHA e BARBOSA (2015, p. 121) existem três posições no Brasil sobre o ativismo judicial: a primeira defende que o protagonismo do judiciário constitui risco à democracia e compromete o equilíbrio e harmonia dos poderes, pois autorizaria que os juízes decidissem conforme suas preferências pessoais, a segunda que reconhece o ativismo como sendo decorrência do sistema pós-Constituição de 1988 e a terceira, que afirma que o protagonismo é consequência direta da necessidade de efetivar a Constituição, sendo que os juízes devem decidir com base nos princípios constitucionais.

Para BARROSO,

o ativismo judicial, até aqui, tem sido parte da solução, e não do problema. Mas ele é um antibiótico poderoso, cujo uso deve ser eventual e controlado. Em dose excessiva, há risco de se morrer da cura. A expansão do Judiciário não deve desviar a atenção da real disfunção que aflige a democracia brasileira: a crise de representatividade, legitimidade e funcionalidade do Poder Legislativo. Precisamos de reforma política. E essa não pode ser feita por juízes (2012, p. 32).

Importante destacar que, mais recentemente, o Código de Processo Civil de 2015 pretendeu reforçar o sistema de precedentes, que na verdade estão mais ligados ao sistema da Common Law do que ao brasileiro da Civil Law, que adota a lei como fonte primordial em decisões judiciais. SACONATO defende que os precedentes se bem empregados poderiam solucionar o problema de no mesmo tribunal existirem decisões distintas sobre casos iguais (2015, p. 95).

Para SACONATO (2015, p. 960), a adoção do sistema de precedentes no Brasil seria o melhor caminho para "minimizar a crise no sistema jurídico brasileiro" e suprir a necessidade de decisões judiciais mais uniformes e estáveis e que "tal uniformização trará maior segurança jurídica e previsibilidade nas decisões, fazendo com que um dos grandes problemas do 
judiciário nacional seja sanado, qual seja o excesso de demandas”, o que contribuiria para o controle do ativismo.

Seja como for, é importante evitar a postura ingênua daqueles que acreditam no texto como meio de garantir segurança jurídica e olham para as normas abertas como um mal a ser evitado. Uma posição como esta, que se coloca em um estágio anterior ao debate entre partido da restauração e partido reformista, não se sustenta de nenhum ponto de vista. É simplesmente um retrocesso no pensamento sobre o direito ou o modo de pensar de um jurista que acabou de sair da máquina do tempo vindo diretamente do século XVII para o século XXI (RODRIGUES, 2011 p. 20).

Representante do poder judiciário, o Ministro Celso de Mello sustentou, em discurso realizado em nome do STF, que as práticas de ativismo judicial,

embora moderadamente desempenhadas por esta Corte em momentos excepcionais, tornam-se uma necessidade institucional, quando os órgãos do Poder Público se omitem ou retardam, excessivamente, o cumprimento de obrigações a que estão sujeitos por expressa determinação do próprio estatuto constitucional, ainda mais se se tiver presente que o Poder Judiciário, tratando-se de comportamentos estatais ofensivos à Constituição, não pode se reduzir a uma posição de pura passividade. (2008, p. 11).

O que se conclui é que a definição da ideia de ativismo deve ser feita de maneira criteriosa, pois ao mesmo tempo em que se exige uma postura dinâmica do judiciário na tomada de decisões, ao mesmo tempo que o sistema constitucional reclama por uma colaboração entre os poderes e que permite uma legitima e intensa participação do judiciário nas decisões do País (pois não raras vezes as questões judicializadas são políticas e sociais), por certo não se poderá admitir a hipertrofia dos poderes e nem a conversão do juiz em legislador.

\section{CONSIDERAÇÕES FINAIS}

Inobstante as críticas progressistas ou conservadoras, o ativismo judicial é uma realidade brasileira inerente ao sistema constitucional adotado com a promulgação da Constituição Federal de 1988 e encerra uma participação mais ampla e intensa do judiciário na concretização dos valores e fins constitucionais, com maior interferência no espaço de atuação que seria dos outros dois Poderes, Executivo e Legislativo.

O protagonismo do Poder Judiciário no Brasil decorre não somente do princípio da universalidade do acesso à jurisdição e da necessidade de utilização do sistema jurídico na mediação das relações sociais, políticas e econômicas, mas também em razão da constitucionalização abrangente que determina a atuação do judiciário para garantir os direitos 
fundamentais expostos e princípios com conceitos abstratos e subjetivos, incluindo-se, portanto, a necessidade de fazer prevalecer a primazia da Constituição da República, muitas vezes transgredida e desrespeitada por não raras vezes conveniente omissão dos poderes públicos.

A realização da Constituição demanda a atividade intelectual do julgador para, além dos obstáculos da própria linguagem, interpretar a norma jurídica, as quais possuem diferentes graus de generalidade, abstração e indeterminação e isso se verifica com maior intensidade quando se tratam dos princípios constitucionais, a justificar a inexistência de respostas únicas e prontas para os problemas jurídicos levados ao poder judiciário.

Os juízes aplicam diferentes métodos de interpretação e - sem ter como base a ilusão de que o direito é completamente imune às influências da política - a realidade revela que as decisões judiciais são influenciadas por fatores múltiplos, eis que os tribunais também estão inseridos no contexto político-institucional, mas tal fato tampouco encerra insegurança jurídica, tendo como base o ordenamento jurídico contemporâneo.

O que se conclui é que mais importante do que estabelecer uma definição conceitual exata de ativismo judicial ou de adjetivá-lo de patologia ou cura, não se pode negar que o Judiciário, ao lado dos demais poderes do Estado, é tão responsável quanto os demais pela realização dos objetivos fundamentais da República Federativa do Brasil e não tem o direito de sentir-se alheio ao dever de construir uma sociedade livre, justa e solidária ou omitir-se diante das ofensas aos direitos fundamentais perpetradas, muitas das vezes, pelo próprio Estado.

\section{BIBLIOGRAFIA}

AZEVEDO CAMPOS, Carlos Alexandre de. Dimensões do ativismo judicial do STF. Rio de Janeiro: Forense, 2014.

BARBOSA, Claudia Maria; ROCHA, Lara Bonemer Azevedo da. O papel dos precedentes para o controle do ativismo judicial no contexto pós-positivista. Revista Brasileira de Políticas Públicas. Brasília: v.5, 2015.

BARROSO, Luís Roberto. Judicialização, ativismo judicial e legitimidade democrática. Rio de Janeiro: $n^{\circ} 1$, v. 5, 2012.

BARROSO, Luís Roberto. Constituição, Democracia e Supremacia Judicial: direito e política no Brasil contemporâneo. Brasília: Revista Jurídica da Presidência, nº 96, v. 12, 2010. Disponível em: 
https://revistajuridica.presidencia.gov.br/index.php/saj/article/view/230/219

CAPPELLETI, Mauro. Juízes legisladores. Tradução de Carlos Alberto Alvaro de Oliveira. Porto Alegre: Sérgio Antonio Fabris Editor, 1999.

MELLO, Celso de. Discurso proferido, em nome do Supremo Tribunal Federal, na solenidade de posse do Ministro Gilmar Mendes, na Presidência da Suprema Corte do Brasil, em 23.04.2008.

Disponível em:

www.stf.gov.br/arquivo/cms/noticiaNoticiaStf/anexo/discursoCM.pdf

FIGUEIREDO, Eduardo Fin; GIBRAN, Sandro Mansur. O ativismo judicial, o princípio da separação dos poderes e a ideia de democracia. Revista Jurídica - Percurso UNICURITIBA. Curitiba, nº 18, v.1, 2016.

Disponível em:

http://revista.unicuritiba.edu.br/index.php/percurso/article/view/1728/1122.

FISCHER, Octavio Campos; LUTZ, Maria Luiza Scherer. Jurisdição constitucional do STF: judicialização da política e o papel contramajoritário. In CORDIOLLI, Marcos (Coord). Cultura \& Inclusão. Curitiba: Instituto Memória, 2016.

GRAU, Eros. Porque tenho medo dos juízes (a interpretação/aplicação do direito e os princípios). São Paulo: Malheiros, $7^{\mathrm{a}}$ ed., 2016.

HUNGARO, Luis Alberto; PEREIRA RIBEIRO, Marcia Carla. Ativismo do Poder Judiciário na concessão de medicamentos $x$ concretização das políticas públicas constitucionais. Revista Direito, Estado e Sociedade - PUC/RIO. Rio de Janeiro, nº 45, 2014.

Disponível em:

https://revistades.jur.puc-rio.br/index.php/revistades/article/view/432.

KNOERR, Fernando Gustavo; LIMA, Liana Taborda. Ativismo judicial como fortalecimento ou afronta ao estado democrático de direito. Revista Jurídica - UNICURITIBA. Curitiba, $\mathrm{n}^{\circ}$ 41, v.4, 2015.

Disponível em:

http://revista.unicuritiba.edu.br/index.php/RevJur/article/view/1387/937.

NALINI, José Roberto. A rebelião da toga. São Paulo: Revista Editora dos Tribunais, $3^{\text {a }}$ ed., 2016. 
RAMOS, Elival da Silva. Ativismo judicial: parâmetros dogmáticos. São Paulo: Saraiva, 2015.

RODRIGUEZ, José Rodrigo. Como decidem as cortes? para uma crítica do direito (brasileiro). Rio de Janeiro: Editora FGV, 2013.

RODRIGUEZ, José Rodrigo. Segurança jurídica e estratégias legislativas: restauração x reforma. São Paulo: Revista Direito GV, mar 2011.

SACONATO, Thais Estevão. A teoria dos precedentes e o controle do ativismo judicial: segurança jurídica e estabilidade nas decisões judiciais. In: Simpósio Revista Eletrônica do Direito, $\mathrm{n}^{\circ} 1,2015$.

Disponível em:

file://C:/Users/Admin/Downloads/1227-1-4323-1-10-20170126.pdf

TASSANARI, Clarissa. Jurisdição e ativismo judicial: limites da atuação do judiciário. Porto Alegre: Livraria do Advogado Editora, 2013.

TEIXEIRA, Anderson Vichinkeski. Ativismo judicial: nos limites entre a racionalidade jurídica e decisão política. São Paulo: Revista Direito GV, v. 8, jan-jun 2012. 